\title{
Notions of "coronavirus" from the perspective of a clinical immunologist and medical historian
}

\author{
Folker Wenzel* \\ Hochschule Furtwangen, Schwenningen, Germany
}

The following notions and the selective literature review should show by mankind already conceived and survived considerations, which are maybe helpful to understand and easier endure the instantaneous "coronavirus" situation. This day and age is not the only one to be hidden by such events, and will also not be the last one. From my point of view our solidarity and humanity will decide to stay alive in the "after that".

If somebody 6 months ago would teach that "keeping distance" is the most important rule to fight against a virus infection most people had not be agreed. Thoughts like a "high specific antibody triggered virus inactivation" (HSATVI) or a "medication guided viral infection intervention" (MGVII) seem much more interestingly (these termini are fictitious), naturally. But it is medical not directly helpful, it is helpful for a better understanding of diseases. And that's the conflict: Do you want a doctor, who though doesn't know why, but his patients are be healed, or a doctor saying: "I'm understanding very exactly what's happened, but nevertheless I'm not able to heal you. Naturally too, the human being makes a wish always for this doctor, who will unite both positive features, in contrast, one may gain experiences to meet those, who apparently understand nothing and can still not heal. And as a physician there is often by yourself no knowing, to which group you belong.

Now take a look at a selective literature review:

First of all, I would like to mention "Herbert Georg Wells" (1866-1946): HG Wells was a writer, historian and sociologist. His novel "The War of the Worlds" was published in 1898: In this novel he describes how aliens (so called Martians) subject the earth and begin to exterminate humanity. Due to technical superiority of the Martians, humans have no chance of countering the attacks of the aliens and seem to be in a lost position: but suddenly the aliens begin to die and humanity survives.

Quote from the novel: “.... .were the Martians—dead!—slain by the putrefactive and disease bacteria against which their systems were unprepared; slain as the red weed was being slain; slain, after all man's devices had failed, by the humblest things that God, in his wisdom, has put upon this earth.

$\ldots$... But by virtue of this natural selection of our kind we have developed resisting power; ..... By the toll of a billion deaths man has bought his birthright of the earth, and it is his against all comers; it would still be his were the Martians ten times as mighty as they are. For neither do men live nor die in vain." \footnotetext{
de.

${ }^{*}$ Corresponding author: Folker Wenzel, Hochschule Furtwangen, Schwenningen, Germany. E-mail: wfo@hs-furtwangen.
} 
This - written in 1898 by a humanities scientist - is now all the more remarkable because at that time there was no understanding of the immune system, especially not at the molecular level. Comparisons can be drawn here with the Nobel Prizes in Physiology or Medicine: 1972 for Gerald Maurice Edelmann, born in New York in 1929, and Rodney Robert Porter, born in Ashton in 1917, for the first description of the antibody structure. Note that the two were not yet born when HG Wells had already written his book.

However, there was of course already previous knowledge: in the Orient, in West Africa and in China smallpox has already been combated by means of so-called "inoculations" for about 2000 years. Until the English country doctor Edward Jenner (1749-1823) developed a less dangerous vaccination method against smallpox at the end of the 18th century (so-called "vaccine"), so that in 1796 the first vaccination of this kind was carried out. Since 1979, smallpox has been considered eradicated (200 years later). Also, the Swedish immunologist Astrid Fagraeus, who first described the release of antibodies from plasma cells in 1948, should be mentioned here. On the bacterial level, Robert Koch (1843-1910) should be mentioned with the description of the anthrax pathogen Bacillus anthracis in 1876 (Nobel Prize for Physiology or Medicine 1905 for the description of tuberculosis pathogens).

A few thoughts on these texts:

1. It is important that humanity immunizes itself. Hiding "foreign contacts" certainly makes us just as vulnerable as we are to very aggressive pathogens. However, our immunity also protects us against invaders (but they usually do not come from space). We can rely on our immune system (for thousands of years).

2. Developments in vaccines and medicines can help, but they take time (to be fully effective for several generations of people), especially if you want to protect all of humanity.

3. And at this point something important for the "science fiction nerds": If we ever conquer alien planets that own or possess something like life, our immune system will also have to fight there, and if these creatures are immunointelligent, so we will probably not be able to gain a foothold there.

4. The importance of the humanities scientists: This is just as high, if not higher, than the importance of natural scientists. In this respect, I recommend reading the text to the end, and you can already look forward to John Ironmonger. If the world had heeded his novel earlier, our economic and social systems would have been better prepared for such a pandemic situation.

5. Regarding these notions I think that we are increasingly seeing one thing: we will not be able to counter future viruses and threats only by vaccines and drugs, but they require a task for society as a whole, with the aim of protecting all of our lives, and we should align our social systems accordingly.

Next, I turn to a brief comparison with the Spanish flu:

Here, from 2007, the publication "Public health interventions and epidemic intensity during the 1918 influenza pandemic" by Richard J. Hatchett, Carter E. Mecher, and Marc Lipsitch published in PNAS (2007) 104 (18) 7582-7587 should be mentioned: At the time of the Spanish flu, the two cities of Philadelphia and St. Louis had planned military parades: Philadelphia let them take place, St. Louis canceled them. The result: While the death toll in Philadelphia at the end of this first wave was 719 deaths/100,000 inhabitants, in St. Louis it was 347. The early actions in St. Louis had saved many lives. In view of this knowledge of 100 years ago, one wonders what our politicians and those of other countries, as well as the appointed experts, have hesitated for so long: All this is not a specific expert knowledge (as well as the exponential spread (which usually takes place over a period of 4 weeks)), but historical, general medical knowledge. It is, of course, more interesting to talk about a healing agent and dream that would solve all problems by one tablet, and then flushes 
money into the coffers of the company that produces it. But this is like in the Middle Ages, when people thought they were turning straw into gold, for this some gave their belongings. Man does not change.

If politics involves ignorance of scientific knowledge, human lives can be destroyed. By contrast, politicians can use quick bold decisions to save people's lives. And while the first ones are already pushing for the so-called "exit strategies": perhaps one should now question the people who have dealt with the historical processes and know about the good sides and the mistakes that were made after 1918 at the time of the Spanish flu. And we should do everything we can to continue to protect human lives.

Let us now consider the novel "The eyes of darkness", 1981, by Dean Ray Koontz (born 1945): Actually, there is only one correspondence with the current reality, namely that a deadly virus (here affecting the brain stem) spreads might, but the author actually mentions Wuhan City as the place of origin (for whatever reason). Against the background of the current coronavirus pandemic, these relatively small parallelisms naturally lead to great interest in the novel and suggest a frightening foreboding of the author (are there people with future visions /knowledge?). Quoting from the novel: "They call the stuff 'Wuhan-400' because it was developed in their RDNA laboratories outside the city of Wuhan. It is the four hundredth viable strain of artificially created microorganisms developed in this research center. 'Wuhan-400' is a perfect weapon." The quote shows that it is a thriller in the East-West concept (for the younger ones among us: keyword: Cold War). However, if you currently want to purchase the mystery thriller, you can currently expect large sums of money, who owns it small recommendation on the side - I would probably sell it to the highly offerings.

Now we come to a novel by John Ironmonger: "Not Forgetting the Whale" from 2015. The novel also contains a viral pandemic, but it does not mainly shed light on the medical aspects rather than the economic aspects: a programmer escapes the big city in which he had developed an artificial intelligence program for an investment company to be faster than everyone else on the stock exchanges of the world. Unfortunately, a global viral pandemic sets in that is highly lethal and has brought the economic system to a standstill. However, he had already fled to a small town on the English coast and, based on his future knowledge, was able to accumulate food supplies in order to save the local population through the crisis. This book shows in a frightening way how the political and economic steps work individually. The author John Ironmonger has certainly done very good research and has incorporated the current management strategies into the book. If only more people had already read this book, and let us hope that the end of the novel will also become our reality: it won't be easy, but in the end everything will be fine.

The humanities scholars are able to describe current situations and think through different scenarios. Obviously, John Ironmonger (already in 2015) shows where an economic system that is designed for efficiency and optimization leads, is vulnerable to disasters and is unable to protect the people it actually works for. The question we all have to ask ourselves: if there are such bright minds among us, why don't we listen to them and why do we allow all-social systems that experts can predict will no longer be able to protect us? And why didn't a politician start addressing the vulnerabilities? Are they no longer listening to the humanities scholars? We would have had already 5 years (parallels to the environmental debate before coronavirus are clear).

Literature:

1. HG Wells: "The war of the worlds", Novel, 1898

2. Richard J. Hatchett, Carter E. Mecher, and Marc Lipsitch: Public health interventions and epidemic intensity during the 1918 influenza pandemic. PNAS (2007) 104 (18) 7582-7587

3. Dean Ray Koontz: "The eyes of darkness", Novel, 1981

4. John Ironmonger: "Not Forgetting the Whale", Novel, 2015 
What can we do?

By these notions, I hope, the crisis could be better understood and easier endured. Especially, statements such as "it is a crisis of a not yet known dimension", I would relativize in view of such historical events. We should use our knowledge and our skills to cope with this and maybe future crises. It would be a pleasure - and was always the way of mankind -, if we can get as many creative solutions on the way as possible and master the crises in common.

Stay healthy, strong with each other and brave! 